\title{
Time-Restricted Feeding in Mice Prevents the Disruption of the Peripheral Circadian Clocks and Its Metabolic Impact during Chronic Jetlag
}

\author{
Louis Desmet ${ }^{1}$, Theo Thijs ${ }^{1}$, Rosalie Mas ${ }^{1}$, Kristin Verbeke ${ }^{2} \mathbb{D}$ and Inge Depoortere ${ }^{1, * \mathbb{D}}$ \\ 1 Translational Research Center for Gastrointestinal Disorders, Gut Peptide Research Lab, University of Leuven, \\ Gasthuisberg, 3000 Leuven, Belgium; Louis.desmet@kuleuven.be (L.D.); Theo.thijs@kuleuven.be (T.T.); \\ r.mas@outlook.be (R.M.) \\ 2 Translational Research Center for Gastrointestinal Disorders, Laboratory of Digestion and Absorption, \\ University of Leuven, Gasthuisberg, 3000 Leuven, Belgium; Kristin.verbeke@kuleuven.be \\ * Correspondence: Inge.depoortere@kuleuven.be
}

Citation: Desmet, L.; Thijs, T.; Mas,

R.; Verbeke, K.; Depoortere, I

Time-Restricted Feeding in Mice

Prevents the Disruption of the Peripheral Circadian Clocks and Its Metabolic Impact during Chronic Jetlag. Nutrients 2021, 13, 3846. https://doi.org/10.3390/nu13113846

Academic Editor: Andrew W McHill

Received: 29 September 2021

Accepted: 27 October 2021

Published: 28 October 2021

Publisher's Note: MDPI stays neutral with regard to jurisdictional claims in published maps and institutional affiliations.

Copyright: (c) 2021 by the authors. Licensee MDPI, Basel, Switzerland. This article is an open access article distributed under the terms and conditions of the Creative Commons Attribution (CC BY) license (https:// creativecommons.org/licenses/by/ $4.0 /)$.

\begin{abstract}
We used time-restricted feeding (TRF) to investigate whether microbial metabolites and the hunger hormone ghrelin can become the dominant entraining factor during chronic jetlag to prevent disruption of the master and peripheral clocks, in order to promote health. Therefore, hypothalamic clock gene and Agrp/Npy mRNA expression were measured in mice that were either chronically jetlagged and fed ad libitum, jetlagged and fed a TRF diet, or not jetlagged and fed a TRF diet. Fecal short-chain fatty acid (SCFA) concentrations, plasma ghrelin and corticosterone levels, and colonic clock gene mRNA expression were measured. Preventing the disruption of the food intake pattern during chronic jetlag using TRF restored the rhythmicity in hypothalamic clock gene mRNA expression of Reverb $\alpha$ but not of Arntl. TRF countered the changes in plasma ghrelin levels and in hypothalamic Npy mRNA expression induced by chronic jetlag, thereby reestablishing the food intake pattern. Increase in body mass induced by chronic jetlag was prevented. Alterations in diurnal fluctuations in fecal SCFAs during chronic jetlag were prevented thereby re-entraining the rhythmic expression of peripheral clock genes. In conclusion, TRF during chronodisruption re-entrains the rhythms in clock gene expression and signals from the gut that regulate food intake to normalize body homeostasis.
\end{abstract}

Keywords: chronic jetlag; circadian clock; ghrelin; short-chain fatty acids; time-restricted feeding

\section{Introduction}

The circadian system rhythmically regulates several gastrointestinal processes enabling organisms to adapt to the daily cycles of nutrient availability [1]. The circadian system involves a central or master clock, located in the suprachiasmatic nucleus (SCN), and peripheral clocks, present in almost every cell of the body. The master clock synchronizes the peripheral clocks to its "standard time", which is mainly generated by external light cues [2]. Neuronal signals; circulating hormones; and metabolites such as glucocorticoids, for example, corticosterone, ensure communication between the SCN and the peripheral clocks [1,3]. Additionally, the peripheral clocks are also synchronized by more local cues, such as nutrients, that control the rhythms in physiology and behavior [4,5]. Some of these food-dependent zeitgebers can feedback phase information to the master clock. This equilibrium results in balanced metabolic functions involving a coordinated response in multiple organs [1].

In mammals, the core of the molecular clockwork is a transcription-translation feedback loop (TTFL) inducing $24 \mathrm{~h}$ rhythms of gene expression. The positive regulators CLOCK and ARNTL form a heterodimer and bind to E-boxes present in genes encoding the negative regulators PER, CRY, and REVERB. These, in turn, repress the activity of the 
CLOCK-ARNTL heterodimer. In addition, these positive and negative regulators control the expression of the so-called clock-controlled genes (CCGs) responsible for rhythmic output signals by acting on E-boxes and/or ROR response elements present in their regulatory regions [6].

A disruption of the circadian system, also called chronodisruption, occurs when exogenous and endogenous effectors disrupt the timing of physiological functions. Common chronodisruptors include light at night and a disturbed eating pattern, as occurs, for example, in shift work, social jetlag, and chronic jetlag [1,7]. When feeding occurs at an unanticipated time, the master clock becomes uncoupled from peripheral clocks to realign with mealtime [8-10]. However, the suboptimal expression of circadian-driven genes compromises metabolic homeostasis. Studies in both humans and mouse models of chronodisruption (genetic or environmental) showed an increase in body mass, a loss in rhythmic physical activity, a dampening of the rhythmicity in the respiratory exchange ratio, glucose intolerance, and dyslipidemia [11-16]. Further, chronodisruption is also associated with diseases such as stroke, Alzheimer's disease, and breast and prostate cancer [11,17-21].

Time-restricted feeding (TRF) or eating (TRE) (when referring to humans) is an eating pattern where the eating window is restricted to a certain time window. This can be used to restore disruptions in the food intake pattern that will reinforce rhythmic activation of clock genes to promote health $[22,23]$. A recent randomized controlled trial showed that TRE in obese patients reduced body mass, energy intake, insulin resistance, oxidative stress, and cardiometabolic health [24]. Similar findings were reported in patients with prediabetes [25]. Further, studies using TRF in mice also showed some promising results in the protection against obesity and obesity related conditions such as adiposity, liver steatosis, glucose intolerance, increased serum cholesterol, and reduced bile acid production [26].

Animals with time-restricted access to food show strong food-anticipatory activity (FAA) before the expected time of food availability [27]. This FAA is independent of the presence of the SCN, suggesting that it is controlled by a food-entrainable oscillator [28,29]. The hunger hormone ghrelin, produced by the stomach, has been shown to increase FAA and to regulate the timing of food intake by inducing the release of AgRP and NPY in the arcuate nucleus [30,31]. In $\mathrm{Arntl}^{-/-}$mice, diurnal rhythms in plasma ghrelin levels and in food intake are abolished, indicating an important interplay between ghrelin, clock genes, and food intake [32,33]. Ablation of AgRP/NPY neurons also impairs adaptations to restricted feeding [34]. Taken together, these findings indicate that ghrelin and AgRP/NPY neurons are important components of the putative food entrainable oscillator during time-restricted feeding.

Timing of food intake is an important factor in the production of several microbial metabolites. Both in humans and mice, the intestinal microbiota and their metabolites display diurnal oscillations that are under influence of feeding rhythms [35-37]. Microbial metabolites such as short-chain fatty acids (SCFA) and bile acids are important entraining factors of peripheral clocks $[16,38]$.

We previously have shown that chronic jetlag in mice disturbed the rhythm in feeding patterns, which correlated with changes in the diurnal rhythms of microbial SCFA levels that affected gut clocks and downstream genes [16]. In the present study, we aim to investigate using an intervention with TRF during the induction of chronic jetlag whether food is an entraining factor during chronodisruption that (1) affects alterations in central clock genes; (2) triggers the food entrainable oscillator, ghrelin, in the stomach to stimulate food intake; (3) feeds back to the hypothalamus to prevent alterations in rhythmicity in Npy/Agrp expression; and (4) prevents the alterations in fecal SCFA levels induced by chronodisruption that, in turn, strengthen/resynchronize the rhythmic activation of the peripheral clock genes to promote health. To assess this, we used three groups of mice: a group of mice that was jetlagged and fed ad libitum (JL AL), a group of mice that was jetlagged and fed a time-restricted feeding diet (JL RF), and a group of control mice fed a time-restricted feeding diet (Ctrl RF). 


\section{Materials and Methods}

\subsection{Mice}

Wild-type C57BL/6J mice were obtained at the age of 12 weeks from Janvier Labs (Le Genest Saint Isle, France). Mice had ad libitum access to water and chow (unless states otherwise) and were housed in a temperature-controlled environment. All experiments were approved by the Ethical committee for Animal Experiments of the KU Leuven and carried out in accordance with the approved guidelines (P187/2017).

\subsection{Experimental Design}

\subsubsection{Chronic Jetlag Model}

Control mice were kept under a $12 \mathrm{~h}$ light/12 h dark cycle (12:12 LD) (ZT $0=$ lights on). Jetlagged mice were housed for four days a week under a 12:12 LD cycle (ZT $0=$ lights on) and the remaining three days of the week under an eight hour advanced 12:12 LD-cycle (ZT 8 = lights on). Chronic jetlag induction lasted for four consecutive weeks (Figure 1A). Zeitgeber time $(\mathrm{ZT})$ refers to the time at which an environmental cue entrains the circadian clock, such as light/dark or feeding/fasting.

(A)

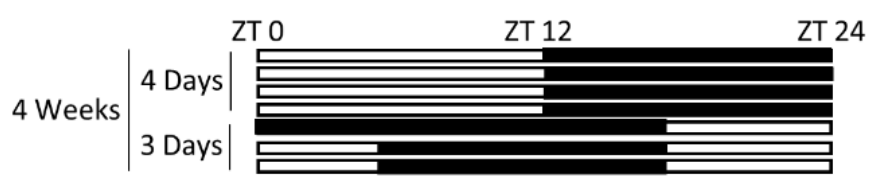

(B)

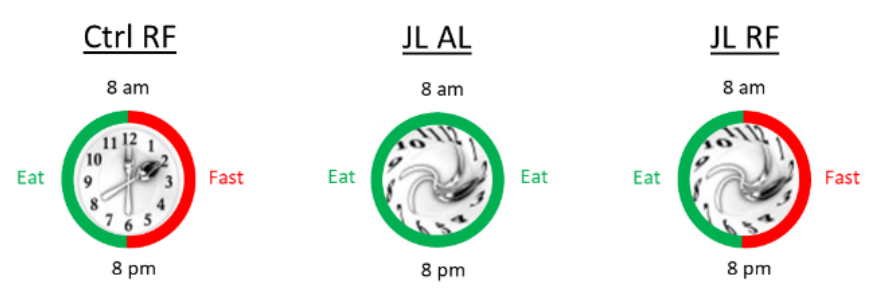

Figure 1. (A) Schematic representation of the jetlag model. The light phase is represented in white; the dark phase is represented in black. ZT = Zeitgeber time. (B) Graphic representation of control mice fed a TRF diet (Ctrl RF), jetlagged mice fed ad libitum (JL AL), and jetlagged mice fed a TRF $\operatorname{diet}(J L R F)$.

\subsubsection{Time-Restricted Feeding Model}

Mice were randomly assigned to three groups each including 48 mice $(\mathrm{N}=8$ mice per time point per group) (Figure 1B). The groups were a jetlag group that was fed a time-restricted feeding diet (JL RF), a second jetlag group that had ad libitum access to food (JL AL), and a control group that was not jetlagged but was fed a night-time restricted feeding diet (Ctrl RF). Mice that received TRF had ad libitum access to normal chow for 12 consecutive hours during the dark (=active) period of the 12:12 LD cycle of control mice. After 12 hours, the chow was removed for the next 12 hours during the light (=inactive) period of the 12:12 LD cycle of the control mice to mimic the food intake pattern of control mice fed ad libitum that consume most of their food intake during the dark phase. Body mass was monitored at the time of sacrifice and once a week at the second day of the normal light/dark cycle (ZT $0=$ lights on) in order to avoid any acute effect of the time-shift during the four weeks of jetlag induction. Food intake was measured in the fourth week of jetlag induction at the second day of the normal light/dark cycle. After four weeks of jetlag induction, the mice were sacrificed over the course of $24 \mathrm{~h}$ at $4 \mathrm{~h}$ intervals. Jetlagged mice were sacrificed when the jetlagged mice were in the same light/dark cycle as control mice, and ZTs were synchronized (i.e., ZT 0 of jetlag mice corresponded to ZT 0 of control mice). The euthanization of the mice from the different groups and timepoints was randomized 
over the second, third, and fourth days of the period that the control and jetlagged mice were in the same light/dark cycle. The luminal content of the distal colon was collected for measurement of SCFA concentrations and stored at $-80^{\circ} \mathrm{C}$. Blood was collected via cardiac puncture and processed for plasma ghrelin measurements. Blood glucose was measured in cardiac blood using a glucometer. Distal colonic mucosa and hypothalamic tissue were isolated, stored in RNAlater (Qiagen, Hilden, Germany), and processed for quantitative real-time PCR (qRT-PCR). All mice $(\mathrm{N}=8)$ were included at each timepoint in the final analyses unless stated otherwise.

\subsection{Analysis of Fecal SCFA Concentrations}

Fecal samples $(100 \mathrm{mg})$ were suspended in $1 \mathrm{~mL}$ of saturated $\mathrm{NaCl}(36 \%)$ solution. An internal standard (50 $\mu \mathrm{L}$ 2-ethylbutyric acid) was added, and the samples were homogenized using glass beads. SCFAs were extracted with ether $(3 \mathrm{~mL})$ in the presence of $\mathrm{H}_{2} \mathrm{SO}_{4}(150 \mu \mathrm{L})$. The ether layer was collected and dried by $\mathrm{Na}_{2} \mathrm{SO}_{4}(50 \mathrm{mg})$. Analysis was performed by gas chromatography-flame ionization detector (Agilent, Santa Clara, CA, USA), with an injection volume of $0.5 \mu \mathrm{L}$. The resulting chromatograms were processed using the Xcalibur software (Thermo Fischer Scientific, Waltham, MA, USA).

\subsection{Quantitative Real-Time PCR}

Total RNA from the distal colonic mucosa and hypothalamus was isolated using the RNeasy Mini Kit (Qiagen, Hilden, Germany). The isolated total RNA was treated with the Turbo DNA-free ${ }^{\mathrm{TM}}$ kit (Thermo Fisher Scientific, Waltham, MA, USA) and reverse transcribed to cDNA using qScript cDNA SuperMix (Quanta BioSciences, Gaithersburg, MD, USA) according to the manufacturer's instructions. qRT-PCR was performed using the Lightcycler 480 (Roche Diagnostics, Basel, Switzerland) with the Lightcycler 480 Sybr Green I Master mix (Roche Diagnostics, Basel, Switzerland). A calibrator was used to correct for inter-run variability between plates. Results were expressed relative to the geometric mean of the normalized expression of three stable housekeeping genes, determined according to the method of Vandesompele, which did not show a circadian rhythm [39] (distal colonic mucosa: $\beta$-actin, TATA box binding protein (Tbp), and cyclophilin (Cycloph); hypothalamus: Cycloph, Tbp, and hydroxymethylbilane synthase (Hmbs)). Primer sequences are shown in Table 1.

Table 1. Primers used for qRT-PCR.

\begin{tabular}{ccc}
\hline Gene & Forward Primer Sequence & Reverse Primer Sequence \\
\hline$\beta$-actin & CCTGTGCTGCTCACCGAGGC & GACCCCGTCTCTCCGGAGTCCATC \\
Cycloph & GGAGATGGCACAGGAGGAAA & CCCGTAGTGCTTCAGCTTGAA \\
Hmbs & CTGAAGGATGTGCCTACCATAC & AAGGTTTCCAGGGTCTTTCC \\
Tbp & AGGATGCTCTAGGGAAGAT & TGAATAGGCTGTGGAGTAAGT \\
A pry & CCGCTCTGCGACACTACAT & TGTCTCAGGGCTGGATCTCT \\
GHS-R & GCGGAGGTGCTAGATCCA & AGGACTCGTGCAGCCTTA \\
Arntl & TCAGGGACCAGAACCACAAA & CCAGCAGAGGATGAAAGCAA \\
Reverb $\alpha$ & CGTTTCTCGACACGCAATAGAT & TCCTGTGGTAGATACGCCAAAA \\
\hline
\end{tabular}

\subsection{Plasma Hormone Measurements}

Plasma samples for total and octanoylated ghrelin were acidified $(0.1 \mathrm{~N} \mathrm{HCl})$ and supplemented with AEBSF to a final concentration of $80 \mathrm{mmol} / \mathrm{L}$ (Sigma-Aldrich, Saint Louis, MO, USA), extracted on a Sep-Pak C18 column (Waters Corporation, Milford, MA, USA), and vacuum-dried. The radioimmunoassay for total and octanoyl ghrelin was performed using an in-house-developed radioimmunoassay as previously described [40]. Plasma corticosterone levels were detected using the Corticosterone EIA Kit (K014-H1; Arbor Assays ${ }^{\circledR}$, Ann Arbor, MI, USA) according to the manufacturer's protocol. 


\subsection{Statistical Analysis}

Results are presented as mean \pm SEM, unless stated otherwise. All statistical analyses were performed in SAS Studio University Edition 9.4. Comparison of body mass between Ctrl RF, JL AL, and JL RF mice over time was performed using a linear mixed model with time as random factor, mouse as subject, and group and time as fixed factor, followed by planned comparison and post hoc testing in Proc Mixed. Comparison of food intake between Ctrl RF, JL AL, and JL RF mice over time was performed using a linear mixed model with time and day/night as random factors; cage as subject; and group, time, and day/night as fixed factors, followed by planned comparison and post hoc testing in Proc Mixed. Since the qPCR data were distributed in a non-normal and/or non-homogeneous manner, we used log-transformed data for all further analyses of the qPCR data. Diurnal rhythm analysis in the jetlag model was calculated using the cosinor procedure developed in SAS, in which the best-fitting cosine curve for a data set was calculated using a non-linear regression model in proc NLIN [41]. Probability values for the best fitting cosine curve are indicated as $p_{\text {cosinor }}$. Differences in acrophase (the time point where the fitted cosine curve reaches its maximum); mesor; and amplitude between Ctrl RF, JL AL, and JL RF mice within one output measure were compared using a non-linear regression model in Proc NLMixed. Differences in acrophase between 2 different output measures was performed using a non-linear mixed regression model with mouse as subject in Proc NLMixed. Significance was accepted at the $5 \%$ level.

\section{Results}

\subsection{TRF Selectively Restored the Disruption of the Central Circadian Clock during Chronic Jetlag}

Altering the light/dark cycle is known to impair the central circadian clock. We investigated whether TRF could avert the effect of disruption of the light/dark cycle during chronic jetlag on the rhythmic expression of clock genes in the hypothalamus. Arntl mRNA expression showed diurnal rhythmicity $\left(p_{\text {cosinor }}<0.001\right)$ in the hypothalamus of the Ctrl RF mice. The acrophase or zeitgeber time (ZT) at which the rhythm peaked was ZT 23h38. This rhythm was abolished in both the JL AL group and the JL RF group (Figure 2A). In contrast, Reverb $\alpha$ mRNA expression displayed a diurnal rhythm in the Ctrl RF group ( $\left.p_{\text {cosinor }}<0.001\right)$, peaking at ZT $11 \mathrm{~h} 47$, which was phase delayed by $4 \mathrm{~h} 20$ in the JL AL group (ZT 16h07; $p_{\text {cosinor }}<0.05$ ) and restored by TRF in the JL RF mice (JL RF: ZT 11h50, $\left.p_{\text {cosinor }}<0.05\right)$ (Figure $2 \mathrm{~B}$ ). Plasma corticosterone levels, which ensure communication between the central and peripheral clocks and act as a read out for the condition of the master clock, were measured as well. Plasma corticosterone levels were diurnal (ZT 14h46; $\left.p_{\text {cosinor }}<0.05\right)$ in the Ctrl RF group but were abolished in the JL AL. Similar to the effects on Arntl mRNA expression, TRF could not restore the loss in rhythmicity induced by chronic jetlag (Figure 2C). Table 2 compares the changes in the acrophase, amplitude, and mesor (=average over $24 \mathrm{~h}$ ) of all the measured parameters of the study in the three groups.

\subsection{TRF Prevented the Increase in Body Mass Induced by Chronic Jetlag}

Disruption of the central clock and consequently of peripheral clocks may affect the food intake pattern during chronic jetlag. Indeed, while mice fed ad libitum normally consume most of their calories during the active phase $(70 \%)$, caloric intake was similar during day and night in JL AL mice (Figure 3A). Total daily food intake was significantly different between all three groups. JL AL mice consumed more calories on a daily basis compared to Ctrl RF mice $(p<0.05)$ and the JL RF mice $(p<0.01)$, while JL RF mice consumed less calories than Ctrl RF mice $(p<0.001)$ (Figure 3B). These differences in caloric intake affected body mass between the three groups (time $\times$ group: $p<0.001$ ). JL AL mice gained more weight than the Ctrl RF mice, but in the JL RF mice, this was prevented after 4 weeks of TRF. Indeed, at week 5, the increase in body mass in the JL RF group was significantly $(p<0.05)$ less than in the JL AL group and did not differ any more from the Ctrl RF group (Figure 3C). 
(A)

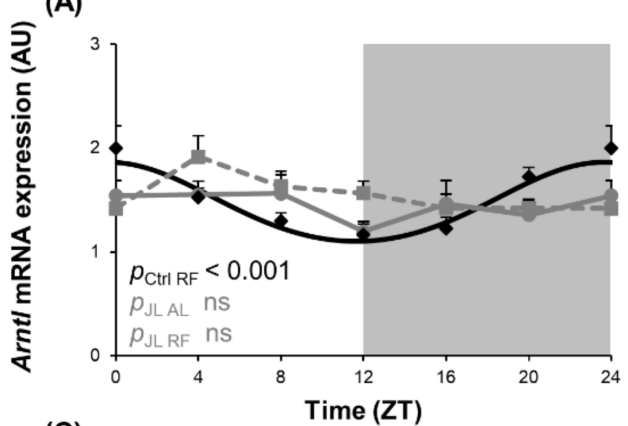

(C)

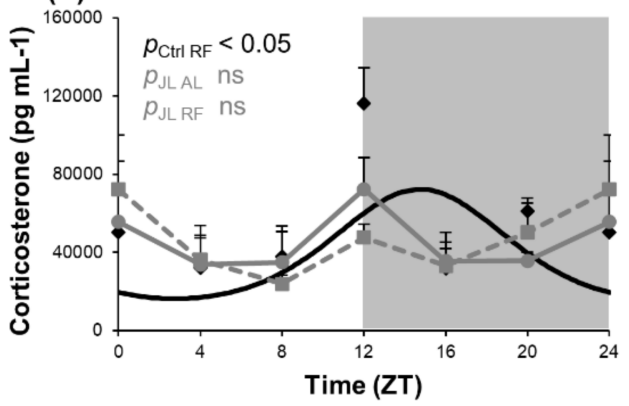

(B)

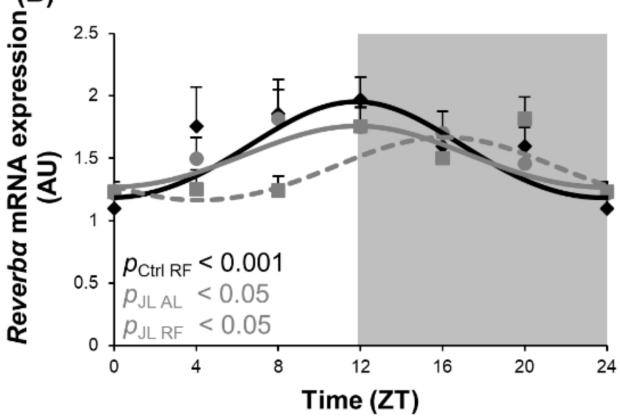

- Ctrl RF
--- JLAL
- JLRF

Figure 2. Effect of time restricted feeding on hypothalamic clock gene mRNA expression and plasma corticosterone levels. (A) Arntl and (B) Reverb $\alpha$ mRNA expression in the mouse hypothalamus ( $n=8$ mice per time point per group) of control mice fed a TRF diet (Ctrl RF), jetlagged mice fed ad libitum (JL AL) and jetlagged mice fed a TRF diet (JL RF). (C) Plasma corticosterone levels ( $n=4$ mice per time point per group). The fitted cosine curve determined by cosinor analysis (period $=24 \mathrm{~h}$ ) are shown in Ctrl RF, JL AL and JL RF mice. The dark phase is shaded grey. Statistics: Non-linear regression (Proc NLIN). $n s$ = not significant. $\mathrm{p}$ values refer to probability values for the best fitting cosine curve.

Table 2. Cosinor values of all measured parameters.

\begin{tabular}{|c|c|c|c|c|c|c|}
\hline & & Condition & $p$ Value Cosinor & Acrophase (h) ( \pm SD) & Amplitude & Mesor ( \pm SD) \\
\hline \multirow{5}{*}{ 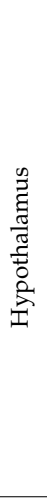 } & \multirow{2}{*}{ 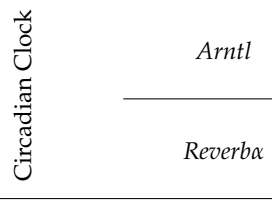 } & $\begin{array}{l}\text { Ctrl RF } \\
\text { JL AL } \\
\text { JL RF }\end{array}$ & $\begin{array}{l}<0.001 \\
\mathrm{~ns} \\
\mathrm{~ns}\end{array}$ & $\begin{array}{c}23 \mathrm{~h} 38( \pm 0 \mathrm{~h} 46) \\
\text { NA } \\
\text { NA }\end{array}$ & $\begin{array}{l}0.38 \\
\text { NA } \\
\text { NA }\end{array}$ & $\begin{array}{c}1.44( \pm 0.05) \\
\text { NA } \\
\text { NA }\end{array}$ \\
\hline & & $\begin{array}{l}\text { Ctrl RF } \\
\text { JL AL } \\
\text { JL RF }\end{array}$ & $\begin{array}{l}<0.001 \\
<0.05 \\
<0.05\end{array}$ & $\begin{array}{c}\text { 11h47 ( } \pm \text { 0h56) } \\
\text { 16h07 }( \pm 1 \mathrm{~h} 11)^{* *} \\
11 \mathrm{~h} 50( \pm 1 \mathrm{~h} 23) \#\end{array}$ & $\begin{array}{l}0.39 \\
0.25 \\
0.25\end{array}$ & $\begin{array}{l}1.52( \pm 0.07) \\
1.39( \pm 0.06) \\
1.49( \pm 0.06)\end{array}$ \\
\hline & GHS-R & $\begin{array}{l}\text { Ctrl RF } \\
\text { JL AL } \\
\text { JL RF }\end{array}$ & $\begin{array}{l}\text { NA } \\
\text { NA } \\
\text { NA }\end{array}$ & $\begin{array}{l}\text { NA } \\
\text { NA } \\
\text { NA }\end{array}$ & $\begin{array}{l}\text { NA } \\
\text { NA } \\
\text { NA }\end{array}$ & $\begin{array}{l}\text { NA } \\
\text { NA } \\
\text { NA }\end{array}$ \\
\hline & Npy & $\begin{array}{l}\text { Ctrl RF } \\
\text { JL AL } \\
\text { JL RF }\end{array}$ & $\begin{array}{c}<0.05 \\
\text { ns } \\
=0.05\end{array}$ & $\begin{array}{c}3 \mathrm{~h} 29( \pm 1 \mathrm{~h} 19) \\
\text { NA } \\
5 \mathrm{~h} 37( \pm 1 \mathrm{~h} 22)\end{array}$ & $\begin{array}{l}0.52 \\
\text { NA } \\
0.38\end{array}$ & $\begin{array}{c}1.71( \pm 0.13) \\
\text { NA } \\
1.37( \pm 0.10) *\end{array}$ \\
\hline & Agrp & $\begin{array}{l}\text { Ctrl RF } \\
\text { JL AL } \\
\text { JL RF }\end{array}$ & $\begin{array}{l}<0.05 \\
<0.05 \\
<0.05\end{array}$ & $\begin{array}{l}\text { 3h02 ( } \pm 1 \mathrm{~h} 24) \\
5 \mathrm{~h} 10( \pm 1 \mathrm{~h} 16) \\
4 \mathrm{~h} 24( \pm 1 \mathrm{~h} 07)\end{array}$ & $\begin{array}{l}0.44 \\
0.35 \\
0.46\end{array}$ & $\begin{array}{c}1.43( \pm 0.12) \\
1.08( \pm 0.08) * \\
1.25( \pm 0.10)\end{array}$ \\
\hline \multirow{4}{*}{ 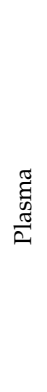 } & Corticosterone & $\begin{array}{l}\text { Ctrl RF } \\
\text { JL AL } \\
\text { JL RF }\end{array}$ & $\begin{array}{c}<0.05 \\
\text { ns } \\
\text { ns }\end{array}$ & $\begin{array}{c}14 \mathrm{~h} 46( \pm 1 \mathrm{~h} 16) \\
\text { NA } \\
\text { NA }\end{array}$ & $\begin{array}{c}27996.33 \\
\text { NA } \\
\text { NA }\end{array}$ & $\begin{array}{c}34348.46( \pm 5488.43) \\
\text { NA } \\
\text { NA } \\
\end{array}$ \\
\hline & Total ghrelin & $\begin{array}{l}\text { Ctrl RF } \\
\text { JL AL } \\
\text { JL RF }\end{array}$ & $\begin{array}{c}<0.001 \\
\text { ns } \\
<0.001\end{array}$ & $\begin{array}{c}8 \mathrm{~h} 03( \pm 0 \mathrm{~h} 29) \\
\text { NA } \\
8 \mathrm{~h} 04( \pm 0 \mathrm{~h} 37)\end{array}$ & $\begin{array}{c}4073.69 \\
\text { NA } \\
2765.73 *\end{array}$ & $\begin{array}{c}9306.82( \pm 351.71) \\
\text { NA } \\
7359.93( \pm 312.97)^{* * *}\end{array}$ \\
\hline & Octanoylated ghrelin & $\begin{array}{l}\text { Ctrl RF } \\
\text { JL AL } \\
\text { JL RF }\end{array}$ & $\begin{array}{c}<0.001 \\
\text { ns } \\
<0.05\end{array}$ & $\begin{array}{c}7 \mathrm{~h} 36( \pm 0 \mathrm{~h} 46) \\
\text { NA } \\
9 \mathrm{~h} 49( \pm 1 \mathrm{~h} 16)\end{array}$ & $\begin{array}{l}16.99 \\
\text { NA } \\
9.73\end{array}$ & $\begin{array}{c}43.89( \pm 2.42) \\
\text { NA } \\
43.07( \pm 2.27)\end{array}$ \\
\hline & Glucose & $\begin{array}{l}\text { Ctrl RF } \\
\text { JL AL } \\
\text { JL RF }\end{array}$ & $\begin{array}{c}<0.05 \\
\text { ns } \\
<0.05\end{array}$ & $\begin{array}{c}4 \mathrm{~h} 42 \text { ( } \pm 1 \mathrm{~h} 18) \\
\text { NA } \\
6 \mathrm{~h} 37( \pm 1 \mathrm{~h} 03)\end{array}$ & $\begin{array}{c}18.88 \\
\text { NA } \\
22.88\end{array}$ & $\begin{array}{c}226.65( \pm 4.92) \\
\text { NA } \\
207.22( \pm 4.45)\end{array}$ \\
\hline
\end{tabular}


Table 2. Cont.

\begin{tabular}{|c|c|c|c|c|c|c|c|}
\hline & & & Condition & $p$ Value Cosinor & Acrophase (h) ( \pm SD) & Amplitude & Mesor ( \pm SD) \\
\hline \multirow{12}{*}{ 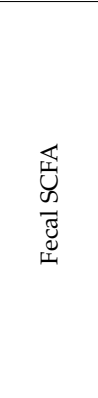 } & \multirow{3}{*}{\multicolumn{2}{|c|}{ Acetate }} & Ctrl RF & $<0.01$ & 4 h28 ( \pm 0 h 57$)$ & 3.84 & $24.62( \pm 0.67)$ \\
\hline & & & JL AL & ns & NA & NA & NA \\
\hline & & & JL RF & $<0.05$ & $6 \mathrm{~h} 39( \pm 1 \mathrm{~h} 14)$ & 3.08 & $25.64( \pm 0.71)$ \\
\hline & \multirow{3}{*}{\multicolumn{2}{|c|}{ Butyrate }} & Ctrl RF & $<0.001$ & $3 \mathrm{~h} 00( \pm 0 \mathrm{~h} 32)$ & 1.78 & $2.66( \pm 0.16)$ \\
\hline & & & JL AL & ns & NA & NA & NA \\
\hline & & & JL RF & $<0.001$ & $3 \mathrm{~h} 13( \pm 0 \mathrm{~h} 41)$ & 1.23 & $2.47( \pm 0.15)$ \\
\hline & \multirow{3}{*}{\multicolumn{2}{|c|}{ Propionate }} & Ctrl RF & $<0.001$ & $5 \mathrm{~h} 44( \pm 0 \mathrm{~h} 41)$ & 0.68 & $2.11( \pm 0.86)$ \\
\hline & & & JL AL & $<0.05$ & $12 \mathrm{~h} 48( \pm 1 \mathrm{~h} 24)^{* * *}$ & 0.44 & $2.89( \pm 0.12)^{* * *}$ \\
\hline & & & JL RF & $<0.05$ & 5 h35 ( \pm 1 h12) \#\#\# & 0.49 & $2.58( \pm 0.11)^{* * *}$ \\
\hline & \multirow{3}{*}{\multicolumn{2}{|c|}{ Total SCFA }} & Ctrl RF & $<0.001$ & 4h14 ( $\pm 0 \mathrm{~h} 45)$ & 2.92 & $29.68( \pm 0.88)$ \\
\hline & & & JL AL & ns & NA & NA & NA \\
\hline & & & JL RF & $<0.05$ & $5 \mathrm{~h} 51( \pm 1 \mathrm{~h} 04)$ & 4.70 & $30.99( \pm 0.93)$ \\
\hline \multirow{6}{*}{ 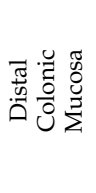 } & \multirow{6}{*}{ 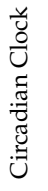 } & & Ctrl RF & $<0.001$ & $1 \mathrm{~h} 07( \pm 0 \mathrm{~h} 11)$ & 0.57 & $0.50( \pm 0.02)$ \\
\hline & & Arntl & JL AL & $<0.001$ & 7h02 ( $\pm 0 \mathrm{~h} 15)^{* * *}$ & $0.44^{* *}$ & $0.52( \pm 0.02)$ \\
\hline & & & JL RF & $<0.001$ & 3h05 ( \pm 0 h12) *** \#\#\# & $0.54 \#$ & $0.49( \pm 0.02)$ \\
\hline & & & Ctrl RF & $<0.001$ & 9 h54 ( \pm 0h11) & 7.60 & $1.97( \pm 0.14)$ \\
\hline & & Reverb $\alpha$ & JL AL & $<0.001$ & $16 \mathrm{~h} 23( \pm 0 \mathrm{~h} 14) * * *$ & $5.03 *$ & $2.10( \pm 0.15)$ \\
\hline & & & JL RF & $<0.001$ & $12 \mathrm{~h} 29( \pm 0 \mathrm{~h} 12)^{* * *} \# \# \#$ & 6.03 & $2.01( \pm 0.15)$ \\
\hline
\end{tabular}

$\mathrm{ns}=$ not significant, NA = not applicable/no rhythm, Ctrl RF = control mice fed a TRF diet, JL AL = jetlagged mice fed ad libitum, JL RF = jetlagged mice fed a TRF diet. Statistics: non-linear regression (Proc NLMixed). ${ }^{*} p<0.05$ compared to Ctrl RF, ${ }^{* *} p<0.01$ compared to $\mathrm{Ctrl} \mathrm{RF}$, ${ }^{* * *} p<0.001$ compared to Ctrl RF, \# $p<0.05$ compared to JL AL, \#\#\# $p<0.001$ compared to JL AL.

(A)

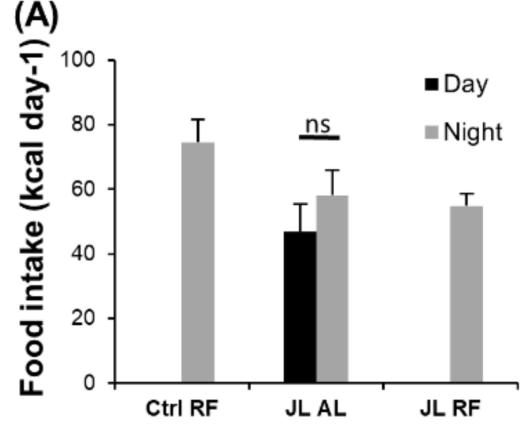

(B)

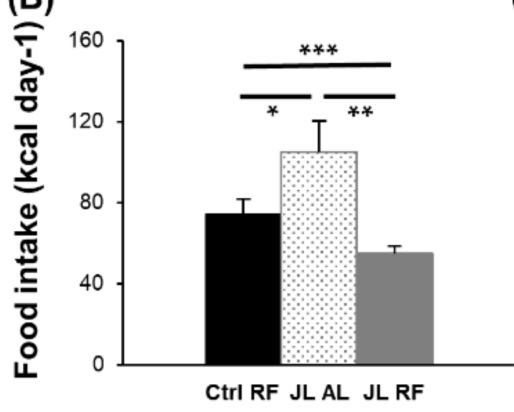

(C)

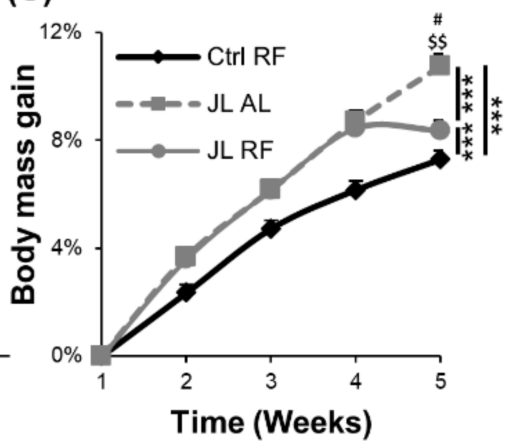

Figure 3. Effect of time-restricted feeding on food intake and body mass. (A) Day/night food intake pattern of control mice fed a TRF diet (Ctrl RF, $N=48$ ), jetlagged mice fed ad libitum (JL $A L, N=48$ ), and jetlagged mice fed a TRF diet (JL RF, $\mathrm{N}=48$ ) at week 4. (B) Total $24 \mathrm{~h}$ caloric intake in Ctrl RF ( $\mathrm{N}=48)$, JL AL ( $=48)$, and JL RF ( $\mathrm{N}=48)$ mice at week 4. (C) Percentage increase in body mass in Ctrl RF ( $\mathrm{N}=48)$, JL AL $(\mathrm{N}=48)$, and JL RF $(\mathrm{N}=48)$ mice. Data are presented as mean \pm SEM. Statistics: mixed model analysis followed by planned comparison and post hoc testing. The interaction effects between the different groups over 5 weeks are depicted as ${ }^{*} p<0.05 ;{ }^{* *} p<0.01 ;{ }^{* * *} p<0.001$. The difference in body mass between the groups at week 5 are depicted as \# $p<0.05$ compared to JL AL; $\$ p<0.01$ compared to Ctrl RF.

\subsection{TRF Partially Prevented the Changes in Rhythmicity of Plasma Ghrelin and Blood Glucose Levels Caused by Chronic Jetlag}

We postulate that TRF may uncouple central and peripheral clocks and entrain ghrelin as a food entrainable oscillator to entrain food anticipatory behavior and food intake during TRF. Both plasma total and octanoylated (=active) ghrelin levels showed a diurnal rhythm in the Ctrl RF group, which peaked at ZT 8h03 $\left(p_{\text {cosinor }}<0.001\right)$ and ZT 7h36 $\left(p_{\text {cosinor }}<0.001\right)$, respectively. Both diurnal ghrelin rhythms were lost in the JL AL group and could be avoided by TRF in the JL RF mice. The acrophases of plasma ghrelin levels of the JL RF mice (total: ZT 8h04, $p_{\text {cosinor }}<0.001$; octanoylated: ZT 9h49, $p_{\text {cosinor }}<0.05$ ) did not differ significantly from the Ctrl RF group. However, the rhythm in plasma total ghrelin levels in the JL RF was dampened with 32\% $(p<0.05)$, and the average plasma total ghrelin level over $24 \mathrm{~h}$ was decreased $(p<0.001)$ compared to the Ctrl RF mice. In contrast, the plasma octanoylated ghrelin levels were not dampened by TRF and did not differ overall over $24 \mathrm{~h}$ (Figure 4A,B). Further, the acrophase of the plasma active ghrelin levels and hypothalamic Reverb $\alpha$ mRNA expression (ZT 11h50) did not differ significantly (non-linear 
mixed model with mesor as random effect) in JL RF mice, suggesting that ghrelin might represent one of the feedback signals from the periphery to the central circadian clock.

(A)
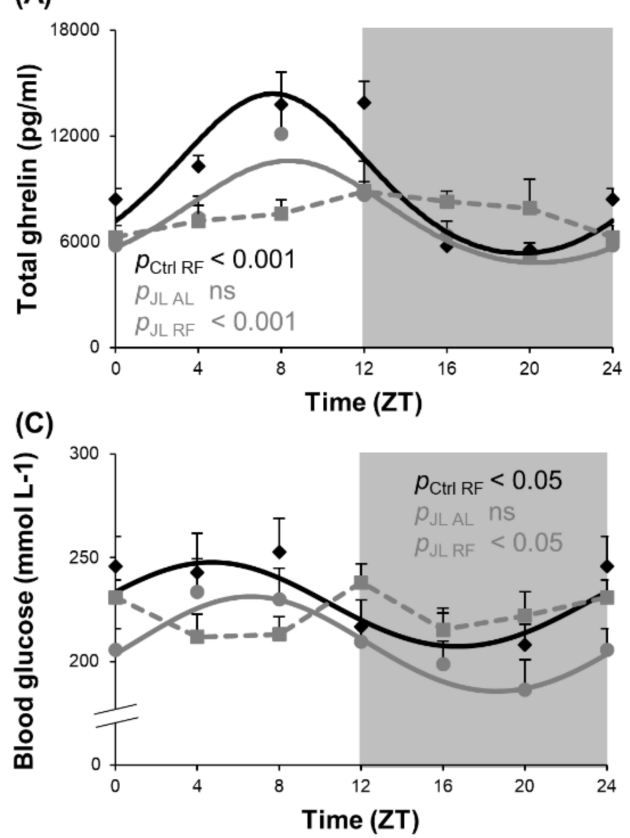

(B)
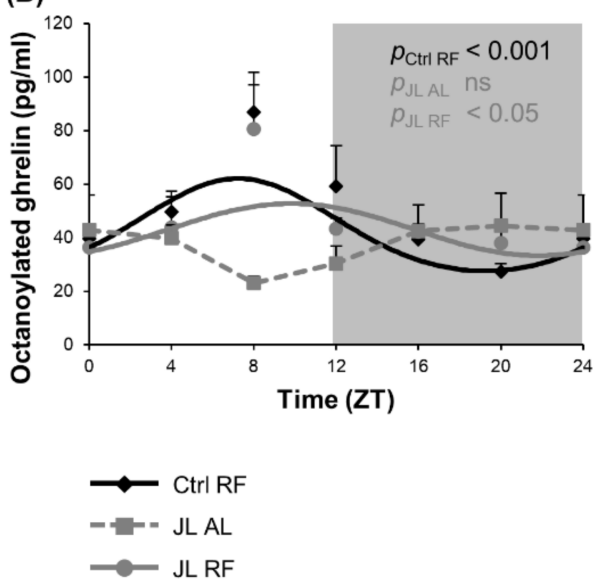

Figure 4. Effect of time restricted feeding on diurnal fluctuations in plasma ghrelin levels and blood glucose levels. Plasma (A) total ghrelin, (B) octanoylated ghrelin and (C) blood glucose levels in control mice fed a TRF diet (Ctrl RF), jetlagged mice fed ad libitum (JL AL) and jetlagged mice fed a TRF diet (JL RF) ( $n=8$ mice per time point per group). The fitted cosine curve determined by cosinor analysis (period $=24 \mathrm{~h}$ ) are shown. The dark phase is shaded grey. Statistics: Non-linear regression (Proc NLIN). ns = not significant. $p$ values refer to probability values for the best fitting cosine curve.

Blood glucose levels were measured as an additional metabolic parameter to determine the effect of preventing the disruption of the rhythm in food intake induced by chronic jetlag using TRF. A diurnal rhythm in blood glucose levels was observed in the Ctrl RF group $\left(p_{\text {cosinor }}<0.05\right)$, peaking at ZT $4 \mathrm{~h} 42$, which was abolished in the JL AL group (Figure $4 \mathrm{C})$. In the JL RF group, a diurnal rhythm $\left(p_{\text {cosinor }}<0.05\right)$ was observed that peaked in phase ZT $6 \mathrm{~h} 37$ with the control group. However, JL RF mice $\left(207.22 \pm 4.45 \mathrm{mmol} \mathrm{L}^{-1}\right)$ had lower average blood glucose concentrations over $24 \mathrm{~h}$ compared to the Ctrl RF mice $\left(226.65 \pm 4.92 \mathrm{mmol} \mathrm{L}^{-1}\right)(p<0.01)$, probably resulting from the decreased total daily food intake in JL RF mice.

\subsection{TRF Prevented the Rhythmicity in Npy mRNA Expression in the Hypothalamus That Was Abolished by Chronic Jetlag}

Ghrelin induces food intake by stimulating the release of the neuropeptides NPY and AgRP via activation of the ghrelin receptor growth hormone secretagogue receptor (GHS-R) in the hypothalamic arcuate nucleus. We hypothesized that prevention of the loss in rhythmicity in plasma ghrelin levels during TRF in jetlagged mice would also prevent alterations in diurnal fluctuations in Npy/Agrp mRNA expression induced by chronic jetlag. GHS-R mRNA expression was not rhythmic in all three groups, with no differences between the groups (Figure 5A). Hypothalamic Npy mRNA expression showed a diurnal rhythm in the Ctrl RF group (ZT 3h29, $p_{\text {cosinor }}<0.05$ ) that was abolished in the JL AL and prevented by TRF in the JL RF mice (JL RF: ZT 5h37, $p_{\text {cosinor }}=0.05$ ) (Figure 5B). However, the acrophase of the plasma ghrelin levels and hypothalamic Npy mRNA expression in both Ctrl RF and JL RF mice differed significantly (non-linear mixed model with mesor as random effect; $p<0.01)$. Overall Npy mRNA expression over $24 \mathrm{~h}$ was decreased $(p<0.05)$ by $20 \%$ in the JL RF mice compared to the Ctrl RF mice, which is in agreement with the 
decreased caloric intake in the JL RF (Figure 3B). Agrp mRNA expression showed diurnal rhythmicity in all three groups $\left(p_{\text {cosinor }}<0.05\right)$, peaking around ZT 4 . The rhythms were not significantly different from each other (Figure 5C). However, chronic jetlag decreased the overall Agrp mRNA expression over $24 \mathrm{~h}$ compared to the Ctrl RF $(p<0.05)$ mice that was prevented by TRF in the JL RF mice.
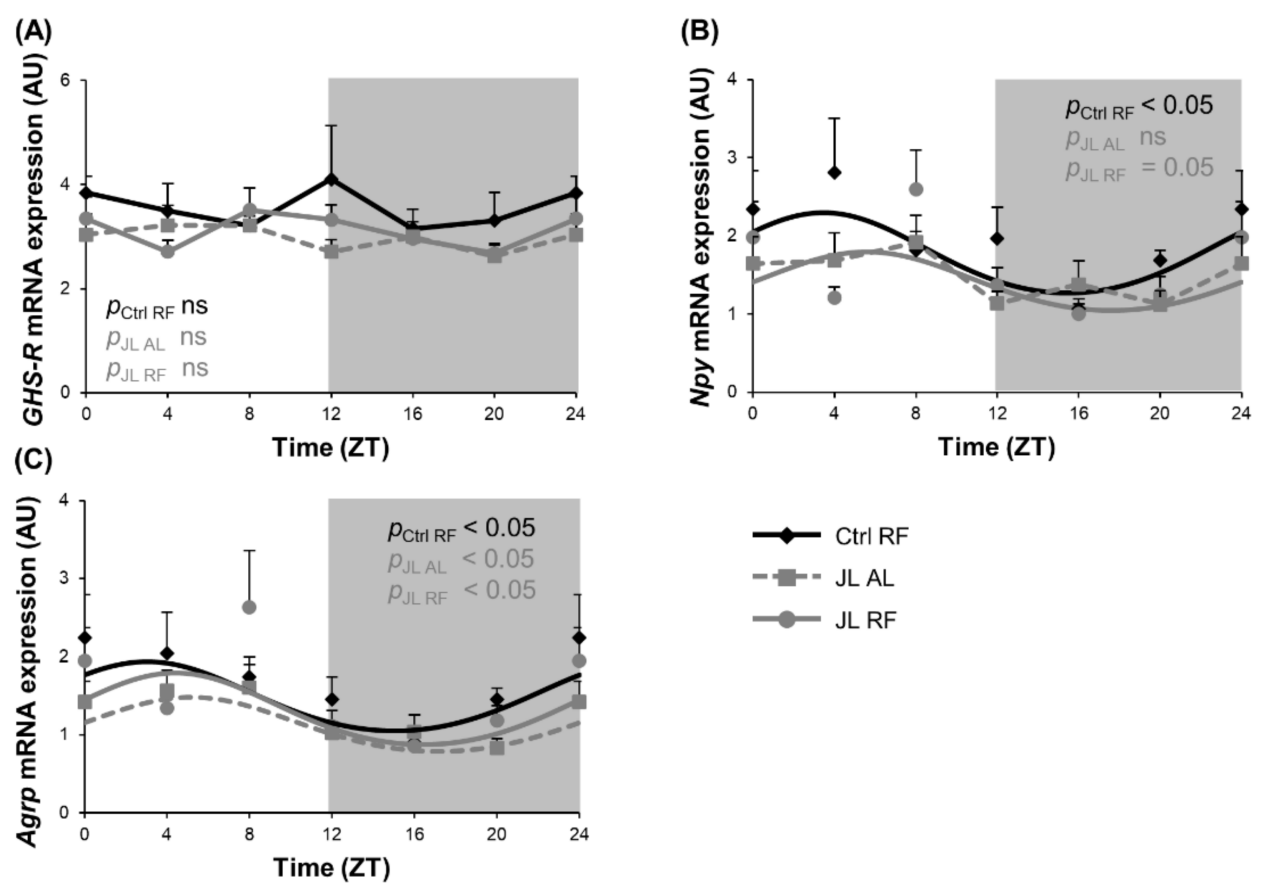

Figure 5. Time restricted feeding prevents the rhythmicity in hypothalamic Npy mRNA expression that is abolished by chronic jetlag. (A) GHS-R, (B) Npy and (C) Agrp mRNA expression in the mouse hypothalamus of control mice fed a TRF diet (Ctrl RF), jetlagged mice fed ad libitum (JL AL) and jetlagged mice fed a TRF diet (JL RF) ( $n=8$ mice per time point per group). The fitted cosine curve determined by cosinor analysis (period $=24 \mathrm{~h}$ ) are shown in Ctrl RF, JL AL and JL RF mice. The dark phase is shaded grey. Statistics: Non-linear regression (Proc NLIN). ns = not significant. $p$ values refer to probability values for the best fitting cosine curve.

\subsection{TRF Prevented Alterations in Diurnal Fluctuations in Fecal SCFA Concentrations Caused by Chronic Jetlag}

We hypothesized that imposing a normal rhythmic food intake pattern in jetlagged mice could prevent changes in diurnal fluctuations in SCFA levels in the colon induced by chronic jetlag. Fecal concentrations of acetate and butyrate showed a diurnal rhythm in the Ctrl RF group (acetate: ZT 4h28, $p_{\text {cosinor }}<0.01$; butyrate: ZT 3, $p_{\text {cosinor }}<0.001$ ) that was lost in the JL AL group and prevented by TRF in the JL RF group (acetate: ZT 6h39, $p_{\text {cosinor }}<0.05$; butyrate ZT $\left.3 h 13, p_{\text {cosinor }}<0.001\right)$. The latter did not differ significantly from the Ctrl RF group (Figure 6A,B). Further, fecal propionate concentrations also showed a diurnal rhythm in the Ctrl RF group ( $p_{\text {cosinor }}<0.001$ ), peaking at ZT 5h44. In contrast to fecal acetate and butyrate concentrations, in the JL AL group, the fecal propionate concentrations still showed a diurnal rhythm $(p<0.05)$ but the rhythm was phase delayed by 7h04 compared to the Crtl RF group $(p<0.001)$. In the JL RF group, the shift in rhythm was prevented (ZT $5 \mathrm{~h} 35, p_{\text {cosinor }}<0.05$ ) and did not differ significantly from the Ctrl RF group (Figure $6 \mathrm{C}$ ). In addition, the average fecal propionate concentration was increased by $36 \%$ in the JL AL mice $(p<0.001)$ and by $22 \%$ in the JL RF mice over $24 \mathrm{~h}(p<0.001)$ compared to the Ctrl RF mice. No difference was observed in average fecal acetate and butyrate concentrations over $24 \mathrm{~h}$ between all three groups. 
(A)
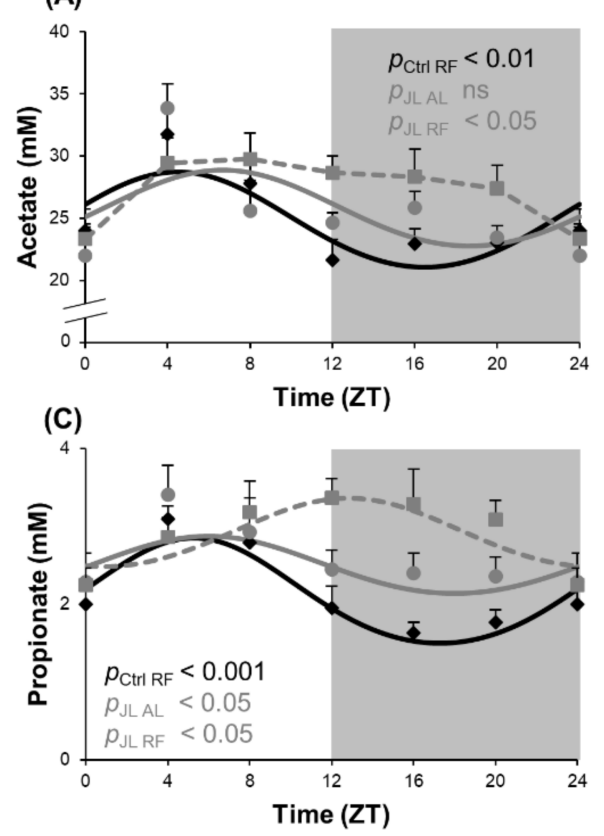

(B)
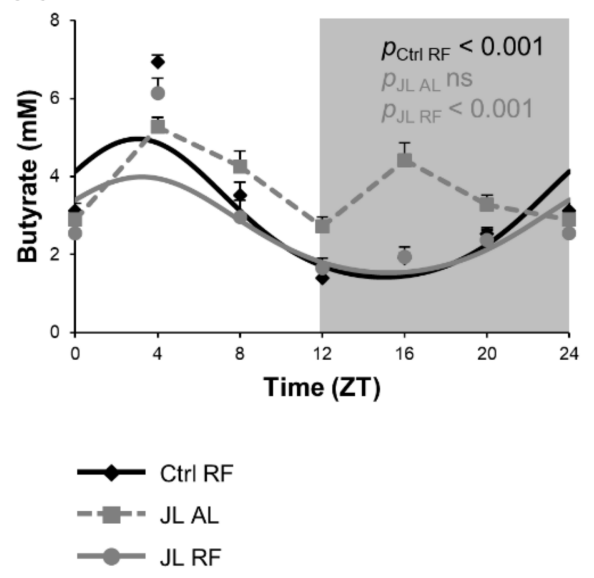

Figure 6. Effect of time restricted feeding on diurnal fluctuations in fecal SCFA concentrations. Fecal (A) acetate, (B) butyrate and (C) propionate concentrations in the distal colon of control mice fed a TRF diet (Ctrl RF), jetlagged mice fed ad libitum (JL AL) and jetlagged mice fed a TRF diet (JL RF) ( $n=8$ mice per time point per group). The fitted cosine curve determined by cosinor analysis (period $=24 \mathrm{~h}$ ) are shown. The dark phase is shaded grey. Statistics: Non-linear regression (Proc NLIN). ns = not significant. $p$-values refer to probability values for the best fitting cosine curve.

\subsection{TRF Partially Prevented Changes in Clock Gene Expression of Colonic Mucosa Caused by Chronic Jetlag}

We previously showed that microbial metabolites such as SCFAs are known to entrain circadian clock gene expression in the colonic mucosa $[16,42]$. Therefore, circadian clock gene expression was studied in the mucosa of the distal colon over $24 \mathrm{~h}$ in Ctrl RF, JL AL, and JL RF mice. Arntl mRNA expression showed diurnal rhythmicity $\left(p_{\text {cosinor }}<0.001\right)$ in all three groups. The rhythm in Arntl mRNA expression in the JL AL group (ZT 7h02) was phase delayed by 5 h55 $(p<0.001)$, and the amplitude was dampened $(p<0.01)$ compared to the Ctrl RF group (ZT 1h07). TRF could partially prevent the phase delay but did not normalize the rhythm in Arntl mRNA expression in the JL RF group (ZT $\left.3 \mathrm{~h} 05, p_{\text {cosinor }}<0.001\right)$. However, the dampening was completely prevented by TRF in the JL RF mice (Figure 7A). Reverb $\alpha$ mRNA expression was also diurnal in all three groups $\left(p_{\text {cosinor }}<0.001\right)$, peaking at ZT 9h54 in the Ctrl RF mice, ZT 16h23 in the JL AL mice, and ZT $12 \mathrm{~h} 29$ in the JL RF mice. Chronodisruption induced, similar to Arntl, a phase delay of $6 \mathrm{~h} 31(p<0.001)$ and a dampening of the amplitude $(p<0.05)$ compared to the Ctrl RF group. TRF in the jetlagged mice could prevent the dampening but only partially prevented the shift in Reverb $\alpha$ mRNA expression (Figure 7B). 
(A)

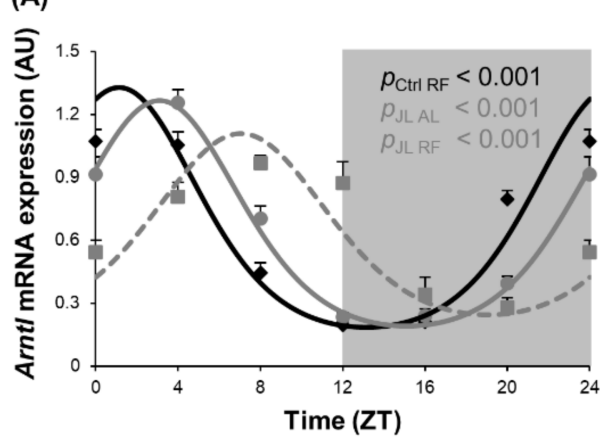

(B)

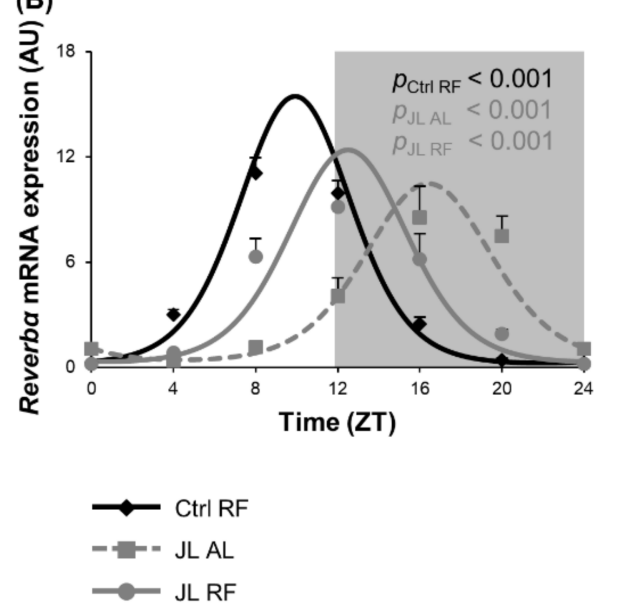

Figure 7. Effect of time restricted feeding on clock gene mRNA expression in the colonic mucosa. (A) Arntl and (B) Reverb $\alpha$ mRNA expression in the mouse distal colonic mucosa of control mice fed a TRF diet (Ctrl RF), jetlagged mice fed ad libitum (JL AL) and jetlagged mice fed a TRF diet (JL RF) ( $\mathrm{N}=8$ mice per time point per group). The fitted cosine curve determined by cosinor analysis (period $=24 \mathrm{~h}$ ) are shown in Ctrl RF, JL AL and JL RF mice. The dark phase is shaded grey. Statistics: Non-linear regression (Proc NLIN). $p$-values refer to probability values for the best fitting cosine curve.

\section{Discussion}

In the present study, we showed that chronic jetlag impaired the central circadian clock, affecting the plasma corticosterone levels that convey the circadian information from the light/dark cycle to the peripheral circadian clocks. TRF selectively prevents the disruption of the central circadian clock as hypothalamic clock gene expression of Reverba, but not of Arntl and corticosterone secretions were restored. During TRF in chronic jetlagged mice, food cues become the dominant zeitgeber preventing the loss in rhythmicity in plasma ghrelin levels and in hypothalamic Npy mRNA expression in order to promote food intake. Avoiding the disruption of the food intake pattern induced by chronodisruption counters the increase in body mass observed during chronodisruption. TRF during chronodisruption prevented the changes in the rhythmicity of fecal SCFAs levels, thereby resynchronizing the rhythmic activation of the peripheral circadian clocks.

To evaluate whether food as an entraining factor in the gut could feedback to the hypothalamus to restore the central circadian clock and its output signals, like corticosterone, we measured circadian clock genes in the hypothalamus and plasma corticosterone levels. TRF could not counteract the loss in the diurnal rhythm of Arntl mRNA expression in the hypothalamus but prevented the phase delay in the rhythm of Reverb $\alpha$ mRNA expression induced by chronic jetlag in the JL RF mice. Strong heterogeneity of entrainment kinetics has already been shown not only between different organs, but also within the molecular clockwork of each tissue [43,44]. Thus, it is possible that if the study lasted longer, Arntl expression could also have been restored in the hypothalamus. Corticosterone secretion is known to be tightly controlled by the $\mathrm{SCN}$ and is therefore a peripheral parameter to evaluate the condition of the central circadian clock $[45,46]$. TRF in the JL RF mice could not prevent the loss in diurnal rhythmicity induced by jetlag, which is in agreement with the fact that the rhythm of the core clock gene, Arntl, was not restored.

Several studies show that chronodisruption (genetic or environmental) disrupts the rhythms in food intake in mice $[14,16,32]$. This is in agreement with our results showing that the JL AL mice consumed equal amounts of calories during the day and night. In addition, the daily consumed calorie intake differed between all three groups. JL RF mice consumed less calories than Ctrl RF mice, probably because they failed to adapt to the new feeding schedule because of the jetlag induction every 3 to 4 days. Ren et al. [47] already 
showed that mice that were fed a TRF diet (only access to food in the dark phase) and exposed to a single (only one day) six hours advanced jetlag needed on average 3-7 days to adapt to the new feeding schedule.

The increased daily caloric intake of JL AL mice compared to Ctrl RF mice increased body mass and could be prevented using TRF during chronodisruption. These results are consistent with studies showing that chronodisrupted high-fat diet-induced obese mice, subjected to a TRF schedule, in both a preventive and therapeutic manner, did not gain significantly more weight than Ctrl mice that were fed ad libitum $[23,26]$. In whole-body Cry1 and Cry2, as well as in liver-specific Arntl and Reverb $\alpha / \beta$ knockout mice, TRF protected mice from excessive weight gain and metabolic diseases compared to both WT and clock gene $\mathrm{KO}$ mice that were fed ad libitum. In the same study, TRF only led to a significant lower body mass compared to the ad libitum fed mice, starting 7 weeks after commencing the feeding regimen [5]. This is in agreement with our results as a difference between the JL AL and JL RF mice became only apparent at week 5 . In humans, studies showed that intermittent fasting (IF), that is, a form of time-restricted eating (TRE), has several positive effects on obesity (reducing body mass/fat) and obesity-related diseases such as lowering of blood pressure, improvement of insulin sensitivity with a reduction of glucose and/or insulin levels, and improvement of lipid profiles [25,48-50].

Studies in SCN-lesioned mice showed that the central circadian clock regulates the feeding/fasting cycle [51,52]. During chronodisruption, food, using TRF, becomes the major zeitgeber and further uncouples the central and peripheral clocks. Our findings show that TRF during chronic jetlag counters the loss in diurnal fluctuations in plasma ghrelin levels that act as a food entrainable oscillator to resynchronize food anticipatory behavior and food intake. LeSauter et al. [53] previously showed that injection of ghrelin increased food anticipatory activity and food intake, and suggested that ghrelin is the food entrainable oscillator that stimulates food intake. The peak in plasma ghrelin levels (ZT 9h49) before the start of the TRF feeding (ZT12) in JL RF mice confirms these findings. Similarly, chronodisruption induced by a HFD was also previously shown to abolish the food anticipatory increase in plasma ghrelin levels [10].

The acrophase of the plasma ghrelin levels (ZT 9h49) and hypothalamic Reverb $\alpha$ mRNA expression (ZT 11h50) did not differ significantly in JL RF mice. It is therefore tempting to speculate that plasma ghrelin feeds back to the central circadian clock to partially restore the rhythmicity in hypothalamic Reverb $\alpha$ but not Arntl mRNA expression during TRF. Indeed, ghrelin has been shown to phase advance spontaneous firing in $\mathrm{SCN}$ slices and the rhythm of PER2::LUC expression in cultured SCN explants expressing the ghrelin receptor [54-56]. Injection of the ghrelin mimetic, GHRP-6, $30 \mathrm{~h}$ after food deprivation induced a phase advance in locomotor activity [54].

Ghrelin exerts its orexigenic function by binding to the ghrelin receptor in the arcuate nucleus and stimulating the release of NPY and AgRP [57-60]. TRF during chronic jetlag prevented the loss in the rhythmicity in hypothalamic Npy expression peaking at ZT 5h37 in JL RF mice similar as in the Ctrl RF mice (ZT 3h29). This acrophase was significantly different from ghrelin (ZT 9h49), indicating that the peak in Npy expression is not directly triggered by ghrelin but occurs during the light phase to replenish the depleted NPY storage after being secreted during the period of food intake in the dark phase. A limitation of our study is that we did not measure changes in NPY protein expression that might fluctuate in parallel with ghrelin. A study in a Arntl KO hypothalamic cell line showed that ARNTL binds to the Npy promotor region, but not of Agrp or Pomc, upon stimulation with bisphenol A or palmitate $[61,62]$. This could possibly explain the loss in rhythm in hypothalamic Npy, but not Agrp mRNA expression, which paralleled the loss in hypothalamic Arntl expression during chronic jetlag. Nonetheless, TRF during chronic jetlag could not restore rhythmicity in hypothalamic Arntl expression, while it did prevent the loss in rhythmicity in Npy expression. It could be that in the absence of a properly function circadian clock food cues become an entraining factor for Npy expression. However, Cedernaes et al. [63] showed that mice with an AgRP-specific ablation of Arntl exhibited a significant reduction 
in food intake during the dark period and an increased intake during the light period. This is not consistent with our results, as Agrp mRNA expression is not affected in the JL AL mice despite a loss in the rhythmicity in Arntl expression.

Preventing the disruption of the food intake pattern in jetlagged mice was also reflected in the fluctuations in blood glucose levels. It was previously shown that a disturbed diurnal eating pattern induced by a disrupted circadian clock resulted in alterations in glucose metabolism in rats [64]. In overweight adults, eTRF (eating between $8 \mathrm{~h}$ and $14 \mathrm{~h}$ ) also improved $24 \mathrm{~h}$ glucose levels [22].

SCFAs show diurnal fluctuations that are affected by alterations in the food intake pattern/diet such as TRF $[16,36,65]$. TRF during chronic jetlag prevented the loss/shift in rhythmicity of fecal SCFA levels. Segers et al. [66] already showed that in $\mathrm{Arntl}^{-/-}$mice, the rhythm of SCFA was absent and could be avoided using TRF. The loss in rhythmicity in SCFA levels in the $\mathrm{Arntl}^{-/-}$mice was probably due to the loss of rhythmicity in the food intake pattern as well [32]. Studies in both human and mice showed that TRF intervention alters both microbial abundance, composition, and metabolites to alleviate several diseases [67-70]. Taken together, our findings suggest that the changes in the rhythmicity in fecal SCFA levels during chronic jetlag are indeed a result of the disrupted food intake pattern and can be prevented using TRF.

We previously showed that SCFAs can entrain the transcript expression of Arntl, Reverbo, and Per2 in primary colonic crypt cultures [16]. Oral administration of SCFAs also has been shown to shift the circadian clock in the liver and kidney in mice [42]. Our current findings show that TRF during chronic jetlag partially prevented the phase delay and countered the decrease in the amplitude of clock genes in the gut mucosa. Some studies already illustrated the effect of TRF on peripheral clock genes. For example, Jamshed et al. [22] showed that eTRF in humans (a six hour eating window between 8 and $14 \mathrm{~h}$ ) increased the expression of several clock genes such as Arntl, Per1, Cry1, Cry2, Reverbo, and $R O R \alpha$ in the blood at $20 \mathrm{~h}$ compared to $8 \mathrm{~h}[71,72]$. Taken together, these findings suggest that the food intake pattern, most likely by affecting the microbial production of SCFA, is indeed an entraining signal for clock genes in the colon. It is possible that if the study lasted longer, the changes in peripheral clock gene expression that are caused by chronic jetlag could be completely prevented. Further, other microbial metabolites such as secondary bile acids have also been shown both in vitro and in vivo to entrain the peripheral circadian clocks [38]. Besides microbial metabolites, metabolism can also affect the circadian clock. Hormones such as insulin, leptin, ghrelin, and glucagon have been demonstrated to acutely affect circadian clock expression [3,73-75]. Thus, it is possible that countering the change in rhythmicity in the SCFA levels alone is not sufficient to prevent the shifts in the circadian clock, but also other metabolic or microbial cues are necessary.

Our results suggest that maintaining a normal food intake pattern during chronodisruption prevents the disruption of the peripheral circadian clocks and the concomitant increase in body mass. Thus, shift-workers can prevent or ameliorate health issues linked to chronodisruption by restricting calorie intake to the light (normal active) phase of the day. Possibly pre- and/or probiotics can be used to further restore the normal peak in fecal SCFAs, although this should be studied in more detail.

In conclusion, our findings suggest that food is a strong entraining cue during chronodisruption that can prevent loss in the rhythmicity in plasma ghrelin levels and hypothalamic Npy expression that regulate the day/night food intake rhythm. As a result, fecal SCFA levels will continue to fluctuate thereby resynchronizing the peripheral circadian clock in the gut. Further, food-induced cues might indirectly feedback to the central circadian clock to restore clock gene expression in the hypothalamus. Thus, TRF could be a good non-invasive measure to prevent certain aspects of chronodisruption that are caused by chronic jetlag. 
Author Contributions: Conceptualization, L.D. and I.D.; data curation, L.D., T.T. and R.M.; formal analysis, L.D., T.T. and R.M.; investigation, L.D., R.M. and I.D.; methodology, L.D., T.T., R.M. and K.V.; resources, I.D.; supervision, I.D.; validation, I.D.; visualization, L.D.; writing一 original draft, L.D. and R.M.; writing-review and editing, L.D., T.T., R.M., K.V. and I.D. All authors have read and agreed to the published version of the manuscript.

Funding: This research was funded by an FWO-SB grant, grant number 1S27618N.

Institutional Review Board Statement: The study was conducted according to the guidelines of the Declaration of Helsinki and approved by the Ethical Committee for Animal Experimentation of the KU Leuven (P187/2017).

Informed Consent Statement: Not applicable.

Data Availability Statement: The data that support the findings of this study are available from the corresponding author upon reasonable request.

Acknowledgments: The authors thank Linda Nys and Greet Vandermeulen for their skillful technical assistance.

Conflicts of Interest: The authors declare no conflict of interest. The funders had no role in the design of the study; in the collection, analyses, or interpretation of data; in the writing of the manuscript; or in the decision to publish the results.

\section{References}

1. Segers, A.; Depoortere, I. Circadian clocks in the digestive system. Nat. Rev. Gastroenterol. Hepatol. 2021, 18, 239-251. [CrossRef] [PubMed]

2. Dibner, C.; Schibler, U. The mammalian circadian timing system: Organization and coordination of central and peripheral clocks. Annu. Rev. Physiol. 2010, 72, 517-549. [CrossRef] [PubMed]

3. Balsalobre, A. Brown Resetting of circadian time in peripheral tissues by glucocorticoid signaling. Science 2000, 289, 2344-2347. [CrossRef] [PubMed]

4. Damiola, F.; Le Minh, N. Restricted feeding uncouples circadian oscillators in peripheral tissues from the central pacemaker in the suprachiasmatic nucleus. Genes Dev. 2000, 14, 2950-2961. [CrossRef] [PubMed]

5. Chaix, A.; Lin, T. Time-Restricted Feeding Prevents Obesity and Metabolic Syndrome in Mice Lacking a Circadian Clock. Cell Metab. 2019, 29, 303-319. [CrossRef]

6. Takahashi, J.S. Transcriptional architecture of the mammalian circadian clock. Nat. Rev. Genet. 2017, 18, 164-179. [CrossRef]

7. Erren, T.C.; Reiter, R.J. Defining chronodisruption. J. Pineal. Res. 2009, 46, 245-247. [CrossRef]

8. Challet, E. The circadian regulation of food intake. Nat. Rev. Endocrinol. 2019, 15, 393-405. [CrossRef] [PubMed]

9. Laermans, J.; Depoortere, I. Chronobesity: Role of the circadian system in the obesity epidemic. Obes. Rev. 2016, 17, 108-125. [CrossRef] [PubMed]

10. Laermans, J.; Broers, C. Shifting the circadian rhythm of feeding in mice induces gastrointestinal, metabolic and immune alterations which are influenced by ghrelin and the core clock gene Bmal1. PLoS ONE 2014, 9, e110176. [CrossRef]

11. Bae, S.A.; Fang, M.Z. At the Interface of Lifestyle, Behavior, and Circadian Rhythms: Metabolic Implications. Front. Nutr. 2019, 6, 132. [CrossRef] [PubMed]

12. Mukherji, A.; Kobiita, A. Shifting eating to the circadian rest phase misaligns the peripheral clocks with the master SCN clock and leads to a metabolic syndrome. Proc. Natl. Acad. Sci. USA 2015, 112, E6691-E6698. [CrossRef]

13. Knutsson, A.; Boggild, H. Gastrointestinal disorders among shift workers. Scand. J. Work Environ. Health 2010, $36,85-95$. [CrossRef] [PubMed]

14. Thaiss, C.A.; Zeevi, D. Transkingdom control of microbiota diurnal oscillations promotes metabolic homeostasis. Cell 2014, 159, 514-529. [CrossRef]

15. Kettner, N.M.; Mayo, S.A. Circadian Dysfunction Induces Leptin Resistance in Mice. Cell Metab. 2015, 22, 448-459. [CrossRef] [PubMed]

16. Desmet, L.; Thijs, T. Chronodisruption by chronic jetlag impacts metabolic and gastrointestinal homeostasis in male mice. Acta Physiol. 2021, e13703. [CrossRef]

17. Logan, R.W.; McClung, C.A. Rhythms of life: Circadian disruption and brain disorders across the lifespan. Nat. Rev. Neurosci. 2019, 20, 49-65. [CrossRef] [PubMed]

18. Crowther, M.E.; Ferguson, S.A. Non-Pharmacological Interventions to Improve Chronic Disease Risk Factors and Sleep in Shift Workers: A Systematic Review and Meta-Analysis. Clocks Sleep 2021, 3, 9. [CrossRef] [PubMed]

19. Hernández-García, J.; Navas-Carrillo, D. Alterations of circadian rhythms and their impact on obesity, metabolic syndrome and cardiovascular diseases. Crit. Rev. Food Sci. Nutr. 2020, 60, 1038-1047. [CrossRef]

20. Morgan, M.N.; Dvuchbabny, S. The Cancer Clock Is (Not) Ticking: Links between Circadian Rhythms and Cancer. Clocks Sleep 2019, 1, 34. [CrossRef] [PubMed] 
21. Homolak, J.; Mudrovčić, M. Circadian Rhythm and Alzheimer's Disease. Med. Sci. 2018, 6, 52. [CrossRef] [PubMed]

22. Jamshed, H.; Beyl, R.A. Early Time-Restricted Feeding Improves 24-Hour Glucose Levels and Affects Markers of the Circadian Clock, Aging, and Autophagy in Humans. Nutrients 2019, 11, 1234. [CrossRef] [PubMed]

23. Hatori, M.; Vollmers, C. Time-restricted feeding without reducing caloric intake prevents metabolic diseases in mice fed a high-fat diet. Cell Metab. 2012, 15, 848-860. [CrossRef] [PubMed]

24. Cienfuegos, S.; Gabel, K. Effects of 4- and 6-h Time-Restricted Feeding on Weight and Cardiometabolic Health: A Randomized Controlled Trial in Adults with Obesity. Cell Metab. 2020, 32, 366-378. [CrossRef] [PubMed]

25. Sutton, E.F.; Beyl, R. Early Time-Restricted Feeding Improves Insulin Sensitivity, Blood Pressure, and Oxidative Stress Even without Weight Loss in Men with Prediabetes. Cell Metab. 2018, 27, 1212-1221. [CrossRef]

26. Chaix, A.; Zarrinpar, A. Time-restricted feeding is a preventative and therapeutic intervention against diverse nutritional challenges. Cell Metab. 2014, 20, 991-1005. [CrossRef]

27. Mistlberger, R.E. Neurobiology of food anticipatory circadian rhythms. Physiol. Behav. 2011, 104, 535-545. [CrossRef]

28. Landry, G.J.; Yamakawa, G.R. The dorsomedial hypothalamic nucleus is not necessary for the expression of circadian foodanticipatory activity in rats. J. Biol. Rhythm. 2007, 22, 467-478. [CrossRef]

29. Power, S.C.; Mistlberger, R.E. Food anticipatory circadian rhythms in mice entrained to long or short day photoperiods. Physiol. Behav. 2020, 222, 112939. [CrossRef]

30. Wang, Q.; Liu, C. Arcuate AgRP neurons mediate orexigenic and glucoregulatory actions of ghrelin. Mol. Metab. 2014, 3, 64-72. [CrossRef] [PubMed]

31. Chen, H.Y.; Trumbauer, M.E. Orexigenic action of peripheral ghrelin is mediated by neuropeptide $\mathrm{Y}$ and agouti-related protein. Endocrinology 2004, 145, 2607-2612. [CrossRef] [PubMed]

32. Laermans, J.; Vancleef, L. Role of the clock gene Bmall and the gastric ghrelin-secreting cell in the circadian regulation of the ghrelin-GOAT system. Sci. Rep. 2015, 5, 16748. [CrossRef]

33. Iijima, M.; Takemi, S. The suppressive effect of REVERBs on ghrelin and GOAT transcription in gastric ghrelin-producing cells. Neuropeptides 2021, 90, 102187. [CrossRef] [PubMed]

34. Tan, K.; Knight, Z.A. Ablation of AgRP neurons impairs adaption to restricted feeding. Mol. Metab. 2014, 3, 694-704. [CrossRef] [PubMed]

35. Zhang, L.; Xue, X. Timing of Calorie Restriction in Mice Impacts Host Metabolic Phenotype with Correlative Changes in Gut Microbiota. Msystems 2019, 4, e00348-19. [CrossRef]

36. Zarrinpar, A.; Chaix, A. Diet and feeding pattern affect the diurnal dynamics of the gut microbiome. Cell Metab. 2014, 20, 1006-1017. [CrossRef]

37. Segers, A.; Desmet, L. The circadian clock regulates the diurnal levels of microbial short-chain fatty acids and their rhythmic effects on colon contractility in mice. Acta Physiol. 2019, 225, e13193. [CrossRef]

38. Govindarajan, K.; MacSharry, J. Unconjugated Bile Acids Influence Expression of Circadian Genes: A Potential Mechanism for Microbe-Host Crosstalk. PLoS ONE 2016, 11, e0167319. [CrossRef]

39. Vandesompele, J.; De Preter, K. Accurate normalization of real-time quantitative RT-PCR data by geometric averaging of multiple internal control genes. Genome Biol. 2002, 3, research0034.1. [CrossRef]

40. Janssen, S.; Laermans, J. Bitter taste receptors and alpha-gustducin regulate the secretion of ghrelin with functional effects on food intake and gastric emptying. Proc. Natl. Acad. Sci. USA 2011, 108, 2094-2099. [CrossRef]

41. Nelson, W.; Tong, Y.L. Methods for cosinor-rhythmometry. Chronobiologia 1979, 6, 305-323. [PubMed]

42. Tahara, Y.; Yamazaki, M. Gut Microbiota-Derived Short Chain Fatty Acids Induce Circadian Clock Entrainment in Mouse Peripheral Tissue. Sci. Rep. 2018, 8, 1395. [CrossRef] [PubMed]

43. Ono, D.; Honma, S. Dissociation of Per1 and Bmal1 circadian rhythms in the suprachiasmatic nucleus in parallel with behavioral outputs. Proc. Natl. Acad. Sci. USA 2017, 114, E3699. [CrossRef]

44. Kiessling, S.; Eichele, G. Adrenal glucocorticoids have a key role in circadian resynchronization in a mouse model of jet lag. J. Clin. Investig. 2010, 120, 2600-2609. [CrossRef] [PubMed]

45. Chung, S.; Lee, E.J. Cooperative roles of the suprachiasmatic nucleus central clock and the adrenal clock in controlling circadian glucocorticoid rhythm. Sci. Rep. 2017, 7, 46404. [CrossRef] [PubMed]

46. Buijs, R.M.; la Fleur, S.E. The suprachiasmatic nucleus balances sympathetic and parasympathetic output to peripheral organs through separate preautonomic neurons. J. Comp. Neurol. 2003, 464, 36-48. [CrossRef]

47. Ren, B.; Ma, C. Impact of Time-Restricted Feeding to Late Night on Adaptation to a 6 h Phase Advance of the Light-Dark Cycle in Mice. Front. Physiol. 2021, 12, 634187. [CrossRef]

48. Longo, V.D.; Mattson, M.P. Fasting: Molecular mechanisms and clinical applications. Cell Metab. 2014, 19, 181-192. [CrossRef] [PubMed]

49. Mattson, M.P.; Allison, D.B. Meal frequency and timing in health and disease. Proc. Natl. Acad. Sci. USA 2014, 111, 16647-16653. [CrossRef] [PubMed]

50. Betts, J.A.; Richardson, J.D. The causal role of breakfast in energy balance and health: A randomized controlled trial in lean adults. Am. J. Clin. Nutr. 2014, 100, 539-547. [CrossRef]

51. Coomans, C.P.; van den Berg, S.A. The suprachiasmatic nucleus controls circadian energy metabolism and hepatic insulin sensitivity. Diabetes 2013, 62, 1102-1108. [CrossRef] 
52. Stoynev, A.G.; Ikonomov, O.C. Feeding pattern and light-dark variations in water intake and renal excretion after suprachiasmatic nuclei lesions in rats. Physiol. Behav. 1982, 29, 35-40. [CrossRef]

53. LeSauter, J.; Hoque, N. Stomach ghrelin-secreting cells as food-entrainable circadian clocks. Proc. Natl. Acad. Sci. USA 2009, 106, 13582-13587. [CrossRef] [PubMed]

54. Yannielli, P.C.; Molyneux, P.C. Ghrelin effects on the circadian system of mice. J. Neurosci. 2007, 27, 2890-2895. [CrossRef]

55. Yi, C.X.; Challet, E. A circulating ghrelin mimetic attenuates light-induced phase delay of mice and light-induced Fos expression in the suprachiasmatic nucleus of rats. Eur. J. Neurosci. 2008, 27, 1965-1972. [CrossRef] [PubMed]

56. Zigman, J.M.; Jones, J.E. Expression of ghrelin receptor mRNA in the rat and the mouse brain. J. Comp. Neurol. 2006, 494, 528-548. [CrossRef] [PubMed]

57. Gil-Campos, M.; Aguilera, C.M.A. Ghrelin: A hormone regulating food intake and energy homeostasis. Br. J. Nutr. 2006, 96, 201-226. [CrossRef]

58. Chen, S.R.; Chen, H. Ghrelin receptors mediate ghrelin-induced excitation of agouti-related protein/neuropeptide Y but not pro-opiomelanocortin neurons. J. Neurochem. 2017, 142, 512-520. [CrossRef] [PubMed]

59. Nakazato, M.; Murakami, N. A role for ghrelin in the central regulation of feeding. Nature 2001, 409, 194-198. [CrossRef] [PubMed]

60. Kamegai, J.; Tamura, H. Chronic central infusion of ghrelin increases hypothalamic neuropeptide Y and Agouti-related protein mRNA levels and body weight in rats. Diabetes 2001, 50, 2438-2443. [CrossRef]

61. Clemenzi, M.N.; Martchenko, A. Analysis of Western diet, palmitate and BMAL1 regulation of neuropeptide Y expression in the murine hypothalamus and BMAL1 knockout cell models. Mol. Cell. Endocrinol. 2020, 507, 110773. [CrossRef] [PubMed]

62. Loganathan, N.; Salehi, A. Bisphenol A Alters Bmal1, Per2, and Rev-Erba mRNA and Requires Bmal1 to Increase Neuropeptide Y Expression in Hypothalamic Neurons. Endocrinology 2019, 160, 181-192. [CrossRef] [PubMed]

63. Cedernaes, J.; Huang, W. Transcriptional Basis for Rhythmic Control of Hunger and Metabolism within the AgRP Neuron. Cell Metab. 2019, 29, 1078-1091. [CrossRef]

64. Versteeg, R.I.; Serlie, M.J. Serotonin, a possible intermediate between disturbed circadian rhythms and metabolic disease. Neuroscience 2015, 301, 155-167. [CrossRef] [PubMed]

65. Tamura, K.; Sasaki, H. The Timing Effects of Soy Protein Intake on Mice Gut Microbiota. Nutrients 2020, 12, 84. [CrossRef] [PubMed]

66. Segers, A.; Desmet, L. Night-time feeding of Bmal1-/- mice restores SCFA rhythms and their effect on ghrelin. J. Endocrinol. 2020, 245, 155-164. [CrossRef]

67. Ye, Y.; Xu, H. Time-Restricted Feeding Reduces the Detrimental Effects of a High-Fat Diet, Possibly by Modulating the Circadian Rhythm of Hepatic Lipid Metabolism and Gut Microbiota. Front. Nutr. 2020, 7, 596285. [CrossRef]

68. Zeb, F.; Wu, X. Time-restricted feeding is associated with changes in human gut microbiota related to nutrient intake. Nutrition 2020, 78, 110797. [CrossRef]

69. Beli, E.; Yan, Y. Restructuring of the Gut Microbiome by Intermittent Fasting Prevents Retinopathy and Prolongs Survival in $\mathrm{db} / \mathrm{db}$ Mice. Diabetes 2018, 67, 1867-1879. [CrossRef]

70. Zeb, F.; Wu, X. Effect of time-restricted feeding on metabolic risk and circadian rhythm associated with gut microbiome in healthy males. Br. J. Nutr. 2020, 123, 1216-1226. [CrossRef]

71. De Goede, P.; Sen, S. Differential effects of diet composition and timing of feeding behavior on rat brown adipose tissue and skeletal muscle peripheral clocks. Neurobiol. Sleep Circadian Rhythm. 2018, 4, 24-33. [CrossRef] [PubMed]

72. Segall, L.A.; Verwey, M. Timed restricted feeding restores the rhythms of expression of the clock protein, Period2, in the oval nucleus of the bed nucleus of the stria terminalis and central nucleus of the amygdala in adrenalectomized rats. Neuroscience 2008, 157, 52-56. [CrossRef] [PubMed]

73. Fu, L.; Patel, M.S. The molecular clock mediates leptin-regulated bone formation. Cell 2005, 122, 803-815. [CrossRef] [PubMed]

74. Sun, X.; Dang, F. Glucagon-CREB/CRTC2 signaling cascade regulates hepatic BMAL1 protein. J. Biol. Chem. 2015, 290, 2189-2197. [CrossRef] [PubMed]

75. Wang, Q.; Yin, Y. Ghrelin Restores the Disruption of the Circadian Clock in Steatotic Liver. Int. J. Mol. Sci. 2018, 19, 3134. [CrossRef] 